\title{
Comportamento sobre prática de higiene das mãos de acompanhantes em enfermarias de internação*
}

\author{
Behavior on hand hygiene practices of companions in inpatient wards
}

Maria Fabiana de Sena Neri ${ }^{1}$, Nelson Miguel Galindo Neto ${ }^{2}$, Cynthia Lima Sampaio ${ }^{1}$, Luis Angel Cendejas Medina ${ }^{1}$, Lívia Moreira Barros ${ }^{3}$, Joselany Áfio Caetano ${ }^{1}$

Objetivo: avaliar a rotina de higiene das mãos de acompanhantes em unidades de internação. Métodos: estudo observacional, com 50 acompanhantes, maiores de 18 anos com linguagem clara. Utilizaram-se de questionário e observação dos momentos de higiene das mãos. Para análise, utilizou-se da estatística descritiva. Resultados: evidenciou-se uso de sabão líquido $(\mathrm{p}=0,939)$, gel alcoólico $(\mathrm{p}=0,939)$, toalha de uso coletivo $(\mathrm{p}=0,939)$, papel descartável $(p=0,939)$, maior frequência depois de usar banheiro $(p<0,000)$ e em instituições de saúde $(p<0,000)$. Os enfermeiros eram os que mais higienizavam as mãos $(p<0,000)$. Higiene preponderante após visita ao paciente $(p<0,000)$ ou em surtos virais $(p<0,000)$. Educação sobre higienização das mãos realizada pela família $(\mathrm{p}=0,253)$ e cuidadores $(\mathrm{p}=0,024)$. Conclusão: as principais práticas foram: lavagem das mãos depois do uso de banheiro e após contato com sujidades ou doente. Ademais, uso do álcool-gel e toalhas descartáveis na higiene das mãos antes das refeições e depois de usar transporte público.

Descritores: Promoção em Saúde; Acompanhante de Paciente; Segurança do Paciente; Higiene das Mãos.

Objective: this study aimed to evaluate the hand hygiene routine of companions in inpatient units. Methods: it was an observational study with 50 companions, aged over 18 years and with clear language. A questionnaire and observation of hand hygiene moments were used. For analysis, descriptive statistics was applied. Results: the use of liquid soap ( $p=0.939)$, alcohol-based hand gel $(p=0.939)$, collective use towel $(p=0.939)$, disposable towels $(\mathrm{p}=0.939)$, higher frequency after going to the bathroom $(\mathrm{p}<0.000)$ and in health institutions $(\mathrm{p}<0.000)$ were verified. Nurses were presented the highest hand hygiene rates $(\mathrm{p}<0.000)$. Prevalent hygiene after visiting the patient $(\mathrm{p}<0.000)$ or viral outbreaks $(\mathrm{p}<0.000)$. Hand hygiene education provided by family $(\mathrm{p}=0.253)$ and caregivers $(\mathrm{p}=0.024)$. Conclusion: the main practices comprised hand hygiene after using the toilet and after contact with dirt or sick people. Furthermore, use of alcohol-based hand gel and disposable towels for hand hygiene before eating and after using public transport.

Descriptors: Health Promotion; Patient Escorts; Patient Safety; Hand Hygiene.

\footnotetext{
*Extraído da dissertação "Tecnologia educacional em higienização das mãos com cuidadores: fundamentada no modelo de promoção da saúde de Nola Pender", Universidade Federal do Ceará, 2018.

${ }^{1}$ Universidade Federal do Ceará. Fortaleza, CE, Brasil.

${ }^{2}$ Instituto Federal de Educação, Ciência e Tecnologia de Pernambuco. Campus Pesqueira, PE, Brasil.

${ }^{3}$ Universidade Estadual Vale do Acaraú. Sobral, CE, Brasil.
} 


\section{Introdução}

As mãos são os principais veículos disseminadores de infecções relacionadas à assistência à saúde. Cotidianamente, em instituições hospitalares, observam-se medidas preventivas para orientação sobre a importância da higienização das mãos para evitar contaminação cruzada. Entretanto, em maioria, essas ações são direcionadas à participação de profissionais de saúde, o que sugere a necessidade de inclusão de pacientes e acompanhantes em atividades preventivas. Ao considerar que os acompanhantes contribuem com o cuidado e manuseiam pacientes com frequência, urge incentivar a prática de higiene das mãos.

Estratégias são realizadas para promoção da higiene das mãos por acompanhantes, como sites informativos e material multimídia ${ }^{(1)}$, televisão, folhetos e educação prestada por profissionais de saúde ${ }^{(2)}$. Porém, poucos estudos relatam frequência e prática de higienização das mãos de acompanhantes. Mensurar esses marcadores requer observação do ambiente de cuidados, no qual as oportunidades, a indicação e ação de higienização das mãos efetivamente são executadas ou não por acompanhantes.

A observação do comportamento contribui com pesquisa acerca da rotina de higiene das mãos, posto que somente perguntas autoaplicadas não são suficientes para aferi-la ${ }^{(3)}$ e, neste cenário, entender as circunstâncias de cuidado é relevante para clareza desta ${ }^{(4)}$. Deste modo, este estudo se justifica por permitir compreender a constância com que acompanhantes que cooperam em enfermarias limpam as mãos, pensando sobre os momentos durante o cuidado, bem como a infraestrutura e os insumos.

Evidência do comportamento de higiene das mãos de acompanhantes é relevante para avaliação do possível risco e capacidade de autocuidado de acompanhantes de paciente em hospital, na perspectiva de controle e/ou redução de infecções associadas aos cuidados de saúde.

Assim, a questão norteadora desta pesquisa foi: quais os comportamentos autorrelatados e obser- vados de acompanhantes para prática de higiene das mãos? Logo, objetivou-se avaliar a rotina de higiene das mãos de acompanhantes em unidades de internação.

\section{Métodos}

Estudo observacional, que utilizou para recolhimento dos dados perguntas fechadas e observação, realizado de novembro de 2017 a janeiro de 2018, em duas unidades de clínica médica de hospital de ensino de Fortaleza, Ceará, Brasil.

O público-alvo, no tempo da pesquisa, era de 60 acompanhantes, os quais foram abordados individualmente e esclarecidos que a participação seria por meio de preenchimento de instrumento e observação, porém estes não foram informados sobre período da observação e instrumento a ser utilizado nesse momento.

Os parâmetros de inclusão dos participantes foram: acompanhante com idade superior a 18 anos que permanecesse no serviço pelo menos duas vezes na semana e possuísse linguagem verbal preservada. Os critérios de exclusão foram: não devolução do questionário autoaplicável preenchido e retorno do questionário, na primeira etapa de coleta de dados.

A amostra foi por conveniência e constituída pelos acompanhantes que responderam aos parâmetros de inclusão e exclusão. Para determinação do número final de participantes, considerou-se intervalo observado de 95\%, medida de dispersão de 0,4; baseou-se na média de ocupação mensal das unidades de internação, no primeiro semestre de 2018, conforme dados do Aplicativo de Gestão para Hospitais Universitários; erro máximo de estimativa de 0,05; correção para população finita, considerando a distribuição de vagas de internação nas enfermarias, utilização real e unidades de isolamento, finalizando amostra total de 50 acompanhantes.

Para recolhimento de dados, foram aplicadas duas ferramentas: uma autoaplicável ${ }^{(5)}$, que continha variáveis referentes ao comportamento de higiene das 
mãos (antes das alimentação, após utilizar o banheiro e o que costumo usar para lavar e secar as mãos); à intenção da lavagem das mãos (é necessário, não é importante); à prática de lavagem das mãos (como é a lavagem das mãos em nossa sociedade e no meu ambiente pessoal); à sensação de potencialidade de infecção de risco e vivências pessoais de infecção; à instrução em higiene das mãos; à percepção da importância de higiene das mãos; e às necessidades de treinamento sobre higiene das mãos. Essas variáveis refletem o desempenho de autoeficácia, ou seja, a capacidade de executar e manter a higiene das mãos, as quais foram anotadas por percepção pessoal, por meio de perguntas abertas, conforme graduação tipo Likert $^{(6)}$, desde menor a maior freqüência da prática de higienização das mãos, com uma pontuação entre 1 e 6 .

O outro instrumento foi usado no momento da observação, fomentadas nas cinco orientações para manejo da higiene das mãos: anterior ao contato com o paciente, precedente à execução de práticas assépticas, após potencialidade de exposição a secreções corporais, depois do contato com o paciente e posterior ao contato com os campos próximos ao paciente. Entretanto, neste estudo, estiveram contemplados quatro momentos, exceto antes de realizar procedimentos assépticos, haja vista que não se configura como momento realizado por acompanhantes.

Assim, os quatro momentos foram: anterior ao contato com o paciente, após potencialidade de exposição a secreções corporais, depois do contato com o paciente e posterior ao contato com os campos próximos ao paciente ${ }^{(7)}$. Esses momentos foram realizados por duas bolsistas do projeto de extensão, previamente treinadas. 0 treinamento ocorreu com leitura, explicação e aplicação do instrumento em unidades distintas daquela do estudo, através de estudo piloto, cada bolsista fez o estudo com cinco acompanhantes para verificar a aplicação adequada do instrumento.

Os acompanhantes foram avaliados em 64 horas, no período de 16 dias. Apenas dois acompanhantes ficavam observados por quarto, com permanên- cia aproximada de duas horas para cada observação, independente do turno de observação. Justifica-se o tempo de observação por se tratar da média de tempo de internação dos pacientes das clínicas, nas quais os dados foram coletados.

Destaca-se que, diante da constante manipulação dos pacientes, pelos acompanhantes, os $120 \mathrm{mi}$ nutos em que se realizaram a observação diária foram suficientes para que houvesse a necessidade de higienização das mãos. 0 intervalo preconizado para permanência de cada momento de observação intentou reduzir o efeito Hawthorne, com base em outra pesquisa $^{(8)}$, visando medir de forma direta este efeito na observação da prática de higiene das mãos.

Com intuito de reduzir essa consequência, importante inconveniência das observações conduzidas, os acompanhantes, através da autorização consciente de esclarecido, foram informados que seriam observados quanto à higienização das mãos durante a participação no cuidado ao paciente, porém sem especificar o exato momento de observação. Por perceber mudança de comportamento em alguns acompanhantes, quanto à higiene das mãos, em decorrência das observações, foram descartados 15 acompanhantes observados.

Na análise, realizou-se aplicação do teste Qui-quadrado para verificar associação entre os produtos frequentemente usados para higiene das mãos. Se o valor $\mathrm{p}$ do teste fosse menor do que o nível de significância desejado, 0,05, rejeitava-se relação entre os produtos mais usados para lavagem e secagem das mãos.

Também, aplicou-se o teste de Wilcoxon para amostra única, o qual é baseado nos postos (ranks) dos valores obtidos, alternativa para o teste de diferenças de médias, uma vez que não houve normalidade dos dados. As hipóteses do teste unicausal são: H0: mediana encontrada igual a 4,00 e H1: mediana encontra maior ou diferente de 4,00. Se o valor $\mathrm{p}$ do teste for menor do que o nível de significância desejado, 0,05, o valor da mediana encontrada será maior que o valor sugerido como mediana 4,00. Ressalta-se 
que a mediana foi definida tendo como base estudo empírico $^{(9)}$.

A pesquisa foi dirigida segundo os padrões éticos exigidos, tendo obtido protocolo de aceitação do Comitê de Ética em Pesquisa da Universidade Federal do Ceará, de acordo com consulta no 2.412.806/2017 e Certificado de Apresentação para Apreciação Ética 76242017.0.0000.5054.

\section{Resultados}

Grande parte dos acompanhantes investigados era do sexo feminino, com idades em meio a 26 e 30 anos, provenientes do interior do Estado, solteiros, com oito anos de ensino formal e católicos. Da amostra, 37 constituíam-se familiares, com grau de parentesco filha ou cônjuge, 26 possuíam renda própria, 24 não tinham renda e cinco eram acompanhantes contratados e remunerados.

O período de cuidados foi modificável, de três a noventa dias, em unidades de internação. No grupo estudado, 36 relataram vivência anterior como acompanhante. Ainda, nesta amostra, nas ocupações, 28 eram empregados, com ênfase para agricultor.

Tabela 1 - Associação entre os produtos frequentemente usados, pelos acompanhantes, para lavagem e secagem das mãos

\begin{tabular}{|c|c|c|c|c|c|}
\hline \multirow{3}{*}{$\begin{array}{l}\text { Produtos frequente- } \\
\text { mente usados para } \\
\text { lavagem das mãos }\end{array}$} & \multicolumn{4}{|c|}{$\begin{array}{l}\text { Insumos mais utilizados para secagem das } \\
\text { mãos }\end{array}$} & \multirow{3}{*}{$\mathbf{p}^{*}$} \\
\hline & $\begin{array}{c}\text { Toalhas } \\
\text { de uso } \\
\text { pessoal }\end{array}$ & $\begin{array}{c}\text { Toalha } \\
\text { de uso } \\
\text { coletivo }\end{array}$ & $\begin{array}{c}\text { Papéis } \\
\text { descartáveis } \\
\text { e outros }\end{array}$ & Total & \\
\hline & n (\%) & n (\%) & n (\%) & n (\%) & \\
\hline Água & $1(2,0)$ & $2(4,0)$ & $2(4,0)$ & $5(10,0)$ & \\
\hline Sabonete líquido & $11(22,0)$ & $15(30,0)$ & $5(10,0)$ & $31(62,0)$ & \\
\hline Álcool em gel & $4(8,0)$ & $5(10,0)$ & $2(4,0)$ & $11(22,0)$ & 0,939 \\
\hline Outros & $1(2,0)$ & $1(2,0)$ & $1(2,0)$ & $3(6,0)$ & \\
\hline Total & $17(34,0)$ & $23(46,0)$ & $10(20,0)$ & $50(100,0)$ & \\
\hline
\end{tabular}

0 produto mais utilizado para higiene das mãos foi o sabão líquido (62,0\%) e o gel alcoólico $(22,0 \%)$. 0 produto frequentemente usado para secagem das mãos era, em geral, a toalha de uso coletivo $(46,0 \%)$ e toalha de uso pessoal $(34,0 \%)$. Segundo o $\mathrm{p}=0,939$, não existiu associação entre os produtos mais usados para lavagem e secagem das mãos.

A Tabela 1 mostra os resultados obtidos dos insumos para lavagem e secagem das mãos, coloca-se em destaque a situação de que os acompanhantes, frequentemente, usavam o sabonete líquido para lavagem das mãos, não houve associação significativa do uso desse antisséptico com o insumo de toalha para secagem das mãos. Neste contexto, vê-se necessário orientar quanto à eficácia do álcool em gel, uma vez que este insumo está disponibilizado em cada enfermaria, à prática correta, pois higienizar as mãos e, ao final utilizar, por exemplo, a toalha disponibilizada para o paciente, não seria satisfatório.

Tabela 2 - Diferença entre as medianas, segundo os momentos de higiene das mãos dos acompanhantes

\begin{tabular}{|c|c|c|c|}
\hline Itens/Respostas & $\begin{array}{c}\text { Média } \pm \text { Desvio } \\
\text { Padrão }\end{array}$ & Mediana* & $\mathbf{p}^{\dagger}$ \\
\hline \multicolumn{4}{|l|}{ Comportamento geral } \\
\hline Antes das alimentações & $5,34 \pm 1,18$ & 6 & $<0,000$ \\
\hline Após de utilizar o banheiro & $5,88 \pm 0,63$ & 6 & $<0,000$ \\
\hline Após usar transportes públicos & $4,72 \pm 1,48$ & 6 & $<0,000$ \\
\hline $\begin{array}{l}\text { Após de ter tocado superfícies que pa- } \\
\text { recem sujas }\end{array}$ & $5,40 \pm 1,19$ & 6 & $<0,000$ \\
\hline Após de ter tocado uma pessoa doente & $5,38 \pm 1,37$ & 6 & $<0,000$ \\
\hline \multicolumn{4}{|l|}{$\begin{array}{l}\text { Comportamento em Enfermarias de In- } \\
\text { ternações }\end{array}$} \\
\hline $\begin{array}{l}\text { Pessoalmente, higienizo minhas mãos } \\
\text { em instituições de cuidados de saúde }\end{array}$ & $5,46 \pm 1,16$ & 6 & $<0,000$ \\
\hline $\begin{array}{l}\text { Da próxima vez que estiver em uma } \\
\text { instituição de saúde, acredito que vou } \\
\text { lavar minhas mãos }\end{array}$ & $5,79 \pm 0,84$ & 6 & $<0,000$ \\
\hline
\end{tabular}

Os acompanhantes realizavam a higienização das mãos com mais frequência após usar o banheiro $(p<0,000)$, depois de ter tocado superfícies que parecem sujas $(\mathrm{p}<0,000)$ e que esses participantes acreditavam que iriam continuar praticando a higienização das mãos quando estivessem em ambiente de cuidados de saúde novamente $(\mathrm{p}<0,000)$. Em relação ao teste de Wilcoxon, em todos os casos, rejeitou-se a 
hipótese nula, ou seja, o valor da mediana foi maior que o valor 4,00 sugerido pelo especialista.

Tabela 3 - Diferença entres as medianas segundo as experiências pessoais quanto aos riscos e ao conhecimento envolvendo a higienização das mãos dos acompanhantes

\begin{tabular}{|c|c|c|c|}
\hline Variáveis & $\begin{array}{c}\text { Média } \pm \text { Desvio } \\
\text { Padrão }\end{array}$ & Mediana* & $\mathbf{p}^{\dagger}$ \\
\hline \multicolumn{4}{|l|}{ Comportamento de autoeficácia } \\
\hline Médicos & $5,50 \pm 1,15$ & 6 & $<0,000$ \\
\hline Enfermeiros & $5,54 \pm 1,05$ & 6 & $<0,000$ \\
\hline Outros trabalhadores de saúde & $4,94 \pm 1,49$ & 6 & 0,000 \\
\hline Pacientes & $4,15 \pm 1,81$ & 4,5 & 0,323 \\
\hline Família e visitantes & $4,21 \pm 1,85$ & 4 & 0,253 \\
\hline \multicolumn{4}{|l|}{$\begin{array}{l}\text { Situações de maior frequência de higieni- } \\
\text { zação das mãos }\end{array}$} \\
\hline Virose por influenza & $5,32 \pm 1,27$ & 6 & $<0,000$ \\
\hline Doenças gastrointestinais & $5,31 \pm 1,35$ & 6 & $<0,000$ \\
\hline Epidemias & $5,17 \pm 1,38$ & 6 & $<0,000$ \\
\hline Após uma visita a um enfermo & $5,55 \pm 1,12$ & 6 & $<0,000$ \\
\hline \multicolumn{4}{|l|}{ Orientação sobre higiene das mãos } \\
\hline Familiares & $4,64 \pm 1,81$ & 6 & 0,024 \\
\hline Amigos & $2,18 \pm 1,57$ & 1 & - \\
\hline Professores do Ensino Fundamental & $4,62 \pm 1,84$ & 6 & 0,044 \\
\hline Professores do Ensino Médio & $4,03 \pm 1,89$ & 4,5 & 0,562 \\
\hline Professores de Ensino Superior & $3,76 \pm 1,98$ & 4 & 0,811 \\
\hline Mídias & $3,84 \pm 2,12$ & 5 & 0,826 \\
\hline Médicos & $3,61 \pm 2,29$ & 4 & 0,982 \\
\hline Profissionais de Saúde & $3,84 \pm 2,18$ & 4 & 0,878 \\
\hline
\end{tabular}

Os acompanhantes consideravam que os enfermeiros eram os que mais higienizam as mãos $(\mathrm{p}<0,000)$ e que as situações importantes para realizar a limpeza das mãos ocorriam após visita ao paciente enfermo $(p<0,000)$ ou em ocorrência de virose por influenza $(\mathrm{p}<0,000)$. Identificou-se, também, que a orientação sobre higiene das mãos foi realizada predominantemente pelos familiares $(p=0,253)$ e por profissionais de saúde $(\mathrm{p}=0,878)$. Em relação ao teste de Wilcoxon, na maioria dos casos, recusou-se a hipótese nula, ou seja, o valor da mediana foi maior que o valor sugerido pelo especialista.

\section{Discussão}

Este estudo apresentou limitações, uma destas refere-se à circunstância de ter sido realizado em única instituição. Além disso, a não participação de acompanhantes de pacientes segregados, os quais podem ser mais vulneráveis a infecções associadas aos cuidados de saúde, pois não era permitido acesso às enfermarias de isolamento. Além disso, a pesquisa foi realizada com base em questionários autoadministrados, em que as más compreensões, não informação ou erros dos entrevistados não puderam ser filtrados. 0 estudo apresenta a impossibilidade de calcular medidas preditivas que favoreçam melhores práticas de cuidados e é impossível determinar a causalidade da não adoção em higiene das mãos por acompanhantes.

O comportamento de lavagem das mãos dos acompanhantes refletiu a necessidade de maior atenção à higiene das mãos em locais de cuidados de saúde, com destaque ao uso do sabonete líquido. 0 desconhecimento dos acompanhantes sobre a eficácia do álcool em gel para prevenção de infecção pode estar relacionada ao fato de que era recente a inserção desse insumo nas instituições de saúde. Em 2010, a Agência Nacional de Vigilância Sanitária regulamentou que nas instituições de saúde no Brasil seria utilizado o álcool - líquido ou gel - para asseio das mãos nas instituições de saúde de todo o país ${ }^{(10)}$.

Em pesquisa com acompanhantes de crianças em creches, as mãos destes foram lavadas com mais frequência, quando toalhas de papel estavam disponíveis, em comparação com toalhas de tecido odds ratio (OR) igual a 1,47 e Intervalo de confiança (IC): 1,00-2,16 ou combinação de toalhas de papel e tecido (OR, 2,13; 95\% IC: 1,32-3,44), inferindo-se que a saúde de acompanhantes de crianças em creche pode ser melhorada. Intervenções para isto devem ponderar os determinantes ambientais, como número e tipo de instalações para toalhas ${ }^{(11)}$. Contexto equipara-se a este estudo, em que a maioria dos acompanhantes no processo de limpeza das mãos usava toalha compartilhada, poucos utilizavam tolhas descartáveis para secar as mãos. 
Com relação aos momentos de asseio das mãos, tem-se como destaque a lavagem das mãos depois do uso de banheiro, seguido por depois de ter tocado superfícies que pareciam sujas e após ter tocado uma pessoa doente. Tanto o comportamento de lavar as mãos após o uso do banheiro, como a lavagem destas durante visita a um paciente no hospital, pode ser influenciado pelo comportamento doméstico e pela disponibilidade de pias mais facilmente visíveis ou exibição de cartazes informativos. Estes recursos foram associados à melhor aderência à lavagem das mãos ${ }^{(12)}$.

Investigação aponta como indicadores para monitoramento das infecções associadas ao cuidado em saúde a substituição do mobiliário degradado e o quantitativo suficiente de pessoas realizando a limpeza/desinfecção ${ }^{(13)}$. Logo, a permanência de mobiliário degradado e ausência ou inadequação no processo de limpeza e desinfecção das superfícies hospitalares pode ampliar a contaminação das mãos, quando acompanhantes, pacientes, visitantes ou profissionais de saúde tocam essas superfícies e não higienizam as mãos nos momentos de contato com o paciente.

Aparelhos digitais podem ser contaminantes de agentes etiológicos causadores de doenças infectocontagiosas. Mãos limpas diminuem esse potencial de risco $^{(14)}$. Assim como a coleta, o transporte, a limpeza e o uso compartilhado de superfícies sujos e o uso compartilhado de utensílios contaminados parecem estar associados aos níveis altos de risco de transmissão de doença ${ }^{(15)}$.

A reduzida associação do comportamento de higiene das mãos dos acompanhantes antes das alimentações e após usar transporte público pode mostrar-se risco de infecções ao manusear o paciente, seja por não lavar as mãos ao sair do transporte público, adentrar na enfermaria e tocar no paciente ou ajudar o paciente a alimentar-se. 0 comer e a preparação de alimentos são situações críticas de lavagem de mãos relacionadas com alimentos ${ }^{(16)}$.

A prática de lavar as mãos é importante para prevenção de doenças causadas pelo contato com micro-organismos bacterianos e fúngicos presentes nas barras e nos assentos dos ônibus de transporte coletivo $^{(17)}$.

Os acompanhantes acreditam que vão higienizar as mãos mais frequentemente na visita posterior em instituição de saúde, pelo fato de estarem, no momento, cuidando de um paciente. Em outro estudo, familiares de pacientes perceberam o hábito de higienizar as mãos como algo "que sempre se faz", entendendo esse cuidado como necessário, independentemente da situação do paciente ${ }^{(6)}$.

Entre os fatores psicossociais que afetam as práticas de lavagem das mãos, o mais importante preditor da frequência da lavagem das mãos foi a autoeficácia ( $\mathrm{p}<0,001)$, seguido por planejamento de ação $(\mathrm{p}<0,001)$ e lembrança $(\mathrm{p}<0,001)^{(18)}$.

Nesta pesquisa, os sujeitos acreditavam lavar as mãos em instituições de cuidados de saúde mais do que os pacientes e menos que os profissionais de saúde. Em pesquisa sobre as necessidades de educação em saúde em pacientes transplantados e a competência de acompanhantes primários, a higienização das mãos esteve entre os aspectos menos compreendidos na educação em saúde. Correlações positivas significantes foram observadas entre o nível de conhecimento em educação em saúde e a competência de cuidado dos acompanhantes primários ${ }^{(19)}$.

Este estudo associou o aumento da frequência de lavagem das mãos à presença de eventos, como visita a um doente, em caso da gripe, doenças gastrointestinais e de epidemias. Estudo de intervenção para avaliar a complacência de asseio das mãos de acompanhantes e crianças, bem como a incidência de infecções gastrointestinais e respiratórias em crianças, concluiu que estas ações podem ser utilizadas como medidas de resultado ${ }^{(11)}$.

A higiene eficaz das mãos dos acompanhantes, neste estudo, foi influenciada principalmente pela família e convívio com profissionais de saúde, o que pode reduzir a propagação de infecções em famílias e instituições de saúde com acompanhantes que estão em cuidados extradomiciliares de pacientes.

A educação em saúde afeta positivamente a efi- 
cácia do autogerenciamento e deve ser realizada de acordo com o estado das necessidades, conhecimento e competência de pacientes e respectivos acompanhantes ${ }^{(19)}$.

Ademais, o empoderamento do paciente é definido como processo no qual os pacientes/acompanhantes familiares entendem o próprio papel e recebem o conhecimento e habilidades deprofissionais de saúde em ambiente que estimule essa participação ${ }^{(20)}$.

Intervenção multifatorial que enfatizou o uso de antissépticos para mãos à base de álcool em casa reduziu a transmissão de doenças gastrointestinais e respiratórias dentro de famílias. Antissépticos para mãos e mensagens educacionais multifacetadas podem ter papel na melhoria das práticas de higiene das mãos dentro do ambiente doméstico ${ }^{(3)}$.

Para familiares, os fatores que afetam as percepções incluem informações prévias sobre higiene das mãos e hospitalizações anteriores para o paciente. $\mathrm{O}$ aumento dos materiais e comportamento de limpeza das mãos pode melhorar o controle de infecções em instalações de saúde ${ }^{(11)}$.

\section{Conclusão}

Neste estudo, ter forte eficácia para lavagem das mãos depois do uso de banheiro e após ter tocado em superfícies sujas ou em doente, atenção ao uso mais frequente do álcool em gel e toalhas descartáveis na higiene das mãos antes das refeições e posteriormente usar transporte público mostraram comportamentos de higiene das mãos de acompanhantes em unidades de internação.

\section{Colaborações}

Neri MFS, Galindo Neto NM, Barros LM e Caetano JA contribuíram com a concepção do projeto, análise de dados, redação do artigo e revisão crítica relevante do conteúdo intelectual e aprovação final da versão a ser publicada. Sampaio CL e Medina LAC colaboraram com a redação do artigo e revisão crítica relevante do conteúdo intelectual.

\section{Referências}

1. Costa TL, Souza OMV, Carneiro HA, Chiquito Netto C, Pegoraro-Krook MI, Dutka JCR. Multimedia material about velopharynx and primary palatoplasty for orientation of caregivers of children with cleft lip and palate. CoDAS. 2016; 28(1):10-6. doi: dx.doi.org/10.1590/2317-1782/20162014126

2. Foà C, Tura GA, Camelli C, Silingardi R, Malavolti $M$, Kuenzer $E$, et al. Hand hygiene in health care settings: the citizens' point of view. Acta Biomed. 2017; 88(1S):40-53. doi: http://doi. org/10.23750/abm.v88i1 -S.6283

3. Alzaher AA, Almudarra SS, Mustafa MH, Gosadi IM. The importance of hand hygiene education on primary schoolgirls' absence due to upper respiratory infections in Saudi Arabia. A cluster randomized controlled trial. Saudi Med J. 2018; 39(10):1044-9. doi: http://doi.org/10.15537/ smj.2018.10.23344

4. Andreotti JT, Ferreira AM, Pinto AMAC, Rigotti MA, Frota OP, Barcelos LS. Avaliação dos serviços: instrumento de avaliação de centros de material e esterilização. Rev Pre Infec Saúde. 2017; 3(3):1-8. doi: https://doi.org/10.26694/repis.v3i3.6580

5. Costa DM, Lopes LKO, Tipple AFV, Castillo RB, $\mathrm{Hu} \mathrm{H}$, Deva AK, et al. Effect of hand hygiene and glove use on cleanliness of reusable surgical instruments. J HospInfect. 2017; 97(4):348-52. doi: http://doi.org/10.1016/j.jhin.2017.06.018

6. Ajzen I. The theory of planned behavior. Organ Behav Hum Decis Process. 1991; 50(2):179-211. doi: doi.org/10.1016/0749-5978(91)90020-T

7. Agência Nacional de Vigilância Sanitária. Manual de referência técnica para a higiene das mãos: para ser utilizado por profissionais de saúde, formadores e observadores de práticas de higiene das mãos [Internet]. 2015 [citado 2019 abr 13]. Disponível em: https://www20.anvisa.gov.br/ segurancadopaciente/index.php/publicacoes/ item/manual-de-referencia-tecnica-para-ahigiene-das-maos

8. Kurtz SL. Measuring and accounting for the Hawthorne effect during a direct overt observational study of intensive care unit nurses. Am J Infect Control. 2017; 45(9):995-1000. doi: 10.1016/j. ajic.2017.03.022 
9. Neri MFS. Tecnologia educacional em higienização das mãos com cuidadores: fundamentada no modelo de promoção da saúde de Nola Pender. Dissertação (Mestrado em Enfermagem) - Universidade Federal do Ceará [Internet]. 2018 [citado 2019 ago. 13]. Disponível em: http://www.repositorio.ufc.br/bitstream/riufc/33370/1/2018_dis_ mfsneri.pdf

10. Agência Nacional de Vigilância Sanitária. Nota Técnica no 01/2018 GVIMS/GGTES/ANVISA: orientações gerais para higiene das mãos em serviços de saúde [Internet]. 2018 [citado 2019 abr 13]. Disponível em: http://portal.anvisa.gov.br/documents/33852/271858/Nota+t\%C3\%A9cni$\mathrm{ca}+\mathrm{n} \% \mathrm{C} 2 \% \mathrm{BA}+01-2018+\mathrm{GVIMS}-\mathrm{GGTES}-\mathrm{ANVISA} /$ ef1b8e18-a36f-41ae-84c9-53860bc2513f

11. Horng LM, Unicomb L, Alam MU, Halder AK, Shoab AK, Ghosh PK, et al. Healthcare worker and family caregiver hand hygiene in Bangladeshi healthcare facilities: results from the Bangladesh National Hygiene Baseline Survey. J Hosp Infect. 2016; 94(3):286-94. doi: https://doi.org/10.1016/j. jhin.2016.08.016

12. Neo JRJ, Sagha-Zadeh R. The influence of spatial configuration on the frequency of use of hand sanitizing stations in health care environments. Am J Infect Control. 2017; 45(6):615-9. doi: https://doi.org/10.1016/j.ajic.2017.01.033

13. Lopes LP, Pio DPM, Pereira FMV, Menegueti MG, Freitas JP, Gir E. Prevalence of oxacillin/methicillinresistant Staphylococcus aureus isolated in the nursing staff. Rev Rene. 2018; 19:e32478. doi: doi. org/10.15253/2175-6783.20181932478

14. Oliveira DB, Bombana CC, Rodrigues GAG, Parussolo L. Caracterização de Staphylococcus aureus isolados da barra de mão de carrinhos e alças de cestas de supermercados. Rev Ciênc Farm Básica Apl [Internet]. 2015 [citado 2019 abr. 10]; 36(3):407-12. Disponível em:http://seer. fcfar.unesp.br/rcfba/index.php/rcfba/article/ view/341

15. Steinert MEP, Hardoim EL, Castro MPPRP. De mãos limpas com as tecnologias digitais. Rev Sustinere. 2016; 4(2):233-52. doi: https://doi. org/10.12957/sustinere.2016.25055

16. Seimetz E, Mosler HJ, Boyayo AM. The influence of contextual and psychosocial factors on handwashing. Am J Trop Med Hyg. 2016; 94(6):140717. doi: https://doi.org/10.4269/ajtmh.15-0657

17. Edmunds KL, Elrahman SA, Bell DJ, Brainard J, Dervisevic S, Fedha TP, et al. Recommendations for dealing with waste contaminated with Ebola virus: a hazard analysis of critical control Points approach. Bull World Health Organ. 2016; 94(6):424-32. doi: https://doi.org/10.2471/ BLT.15.163931

18. Vaidotas M, Yokota PK, Marra AR, Camargo TZ, Victor Eda S, Gysi DM, et al. Measuring hand hygiene compliance rates at hospital entrances. Am J Infect Control. 2015; 43(7):694-6. doi: https://doi.org/10.1016/j.ajic.2015.03.008

19. Xie J, Ming Y, Ding S, Wu X, Liu J, Liu L, et al. Rising Need for Health Education Among Renal Transplant Patients and Caregiving Competence in Care Providers. Prog Transplant. 2017; 27(2):180-6. doi: https://doi.org/10.1177/1526924817699962

20. Zellmer C, Blakney R, Van Hoof S. Impact of sink location on hand hygiene compliance for Clostridium difficile infection. Am J Infect Contr. 2015; 43(4):387-9. doi: http://dx.doi.org/10.1016/j. ajic.2014.12.016 